\title{
The role of hormones and aromatase inhibitors on breast tumor growth and general health in a postmenopausal mouse model
}

\author{
Arunkumar Arumugam¹, Elaine A Lissner ${ }^{2}$ and Rajkumar Lakshmanaswamy ${ }^{1 *}$
}

\begin{abstract}
Background: Breast cancer is the most frequently diagnosed cancer in women in the United States. Approximately $70 \%$ of breast cancers are diagnosed in postmenopausal women. Major clinical trials and experimental studies showed that aromatase inhibitors are effective against postmenopausal breast cancer. Despite their effectiveness in reducing tumor recurrence, aromatase inhibitors have adverse effects on the cardiovascular system and increase osteoporosis and bone fractures. Our study is aimed at investigating the role of natural steroid hormones on serum cardiovascular and bone resorption markers in an established mouse model mimicking postmenopausal breast cancer.
\end{abstract}

Methods: Ovariectomized nude mice were transplanted with MCF-7 breast cancer cells constitutively expressing aromatase. The mice were treated with different combinations and doses of steroids, [estrogen ( $25 \mathrm{pg}, 40 \mathrm{pg}$, $100 \mathrm{pg}$ ), progesterone (6 $\mathrm{ng}$ ) and testosterone (50 ng)] along with dehydroepiandrostenedione (100 ug). Serum levels of $\mathrm{HDL}$, $L D L N L D L$, free and total cholesterol, total and bone specific alkaline phosphatase and triglycerides were analyzed after 5, 10 and 15 months.

Results: Free cholesterol and LDLNLDL levels in serum were reduced in groups mimicking estrous cycle and menstrual cycle hormones treatment. HDL cholesterol was increased in all the hormone treated groups except the estrous cycle-mimicking group. Bone specific alkaline phosphatase was decreased in menstrual cycle levels of estrogen and progesterone treatment.

Conclusions: All together our results show that use of natural hormones in appropriate combinations have beneficial effects on cardiac and bone toxicity, along with better tumor reduction than current treatments.

Keywords: Postmenopausal breast cancer, Aromatase inhibitors, Hormones, Bone markers, Cardiac markers

\section{Background}

Breast cancer is one of the most common cancers among women, with more than one million cases and nearly 600,000 deaths annually worldwide [1]. Breast cancer incidence rates vary markedly among countries. Breast cancer is the most frequently diagnosed cancer in women in the United States. Due to the high incidence rate along with social and cultural considerations, breast cancer ranks highest among women's health concerns. Despite the

\footnotetext{
* Correspondence: rajkumar.lakshmanaswamy@ttuhsc.edu

${ }^{1}$ Center of Excellence in Cancer Research, Department of Biomedical Sciences, Paul L. Foster School of Medicine, Texas Tech University Health Sciences Center, El Paso, Texas 79905, USA

Full list of author information is available at the end of the article
}

advancement of new preventive strategies, the incidence of breast cancer has remained the same since 2005 [2]. Approximately $70 \%$ of breast cancers are diagnosed in postmenopausal women [3].

The steroid hormones estrogen and progesterone have long been thought to play a role in the etiology of breast cancer. Apart from breast cancer growth, these hormones also influence various physiological processes. After the cessation of ovarian function, a significant decrease in the ovarian hormones estrogen and progesterone leads to a variety of symptoms known as postmenopausal symptoms. The most common symptoms include hot flashes, night sweats, mood swings, and sleep disturbances. These symptoms negatively influence a woman's quality of life. 
Additionally, estrogens have beneficial actions on bone and lipid metabolism and cardiovascular function [4-7]. To alleviate postmenopausal symptoms, hormone replacement therapy (HRT) is used as a treatment. In particular, HRT has been shown to alleviate vasomotor symptoms, aid in the prevention of osteoporosis and improve serum lipid profiles [8-11].

Despite positive effects of HRT, some exogenous hormones have been shown to increase the incidence of breast cancer. The Women's Health Initiative (WHI) study, which utilized conjugated equine estrogen (0.625 mg per day) and medroxyprogesterone acetate (2.5 mg per day), revealed a $24 \%$ increased risk for invasive breast cancer [12], with no major beneficial effects against cardiovascular disease, stroke, and thromboembolic diseases [13]. These findings resulted in a $63 \%$ reduction of HRT use within 3 months after the WHI publication. However, recent analyses of the WHI data have shown that estrogen replacement therapy alone (without medroxyprogesterone acetate) actually decreased the risk of breast cancer [12].

Aromatase inhibitors (AIs) are widely used for the adjuvant treatment of postmenopausal breast cancer, generally prescribed for five years at the conclusion of surgery, chemotherapy and/or radiation treatment. AIs target the aromatase enzyme, which converts adrenal androgens to estrogens. After the Arimidex, Tamoxifen, Alone or in Combination (ATAC) trial showed AIs are equally effective to tamoxifen, the FDA approved AIs as a first-line endocrine therapy for preventing recurrence of hormone-positive postmenopausal breast cancer [14-18]. However, several observational and meta-analyses revealed that AIs used for the prevention of postmenopausal breast cancer reduce cancer recurrence but also have serious side effects on bone and the cardiovascular system. AIs cause severe joint pain, hip fracture, increased osteoporosis risk, and musculoskeletal pain. Loss of learning and memory function is also an important adverse effect associated with AI treatment that can lead to dementia at later stages $[19,20]$. In a large cohort study using 8,769 breast cancer patients, approximately $51 \%$ of the patients discontinued their adjuvant hormonal therapies including tamoxifen and AIs due to the adverse side effects [21]. Therefore, it is imperative to find alternative treatment regimens with fewer unfavorable side effects for postmenopausal breast cancer patients.

From the available literature and published data, it is clear that currently used treatments reduce breast cancer recurrence but also have serious undesirable side effects that limit their usefulness. In this study, we aimed to develop hormone treatments that will provide similar or improved survival rates compared with the drugs used currently, but without the harmful and undesirable side effects.

\section{Methods}

\section{Animals}

Female athymic nude mice were obtained from Harlan Laboratories $^{\mathrm{TM}}$ (San Diego, CA). Animals were housed in groups in a pathogen-free environment under controlled light and humidity conditions, and received food and water ad libitum. The mice were ovariectomized at 10 weeks of age. One week later, mice received transplants of MCF-7 cells stably transfected with the human aromatase gene. Each experimental group had 15 animals and when necessary for validation, experiments were repeated. All procedures followed the Animal Care and Use Committee guidelines of Texas Tech University Health Sciences Center.

\section{Cell culture and xenograft transplantation}

MCF-7 cells stably transfected with the human placental aromatase gene (MCF-7-ARO) were cultured in Eagle's minimum essential media containing $10 \%$ fetal bovine serum and antibiotics. Subconfluent MCF-7-ARO cells were trypsinized and suspended in collagen matrix solution (85\% collagen and $15 \%$ neutralizing buffer) to make a concentration of $310^{7}$ cells $/ \mathrm{ml}$. At 11 weeks of age, ovariectomized mice were inoculated with MCF-7-ARO cells. Each mouse was inoculated with $0.1 \mathrm{ml}$ cell suspension in both flanks $\left(\sim 310^{6}\right.$ cells/site). Tumor growth was determined by measuring tumor volume using the formula $4 / 3 r_{1}^{2} r_{2}$, where $r_{1}$ is the minor radius and $r_{2}$ is the major radius.

\section{Hormone treatments}

Ten-week-old mice were ovariectomized and randomly separated into 8 groups consisting of 15 animals per group. Mice in all groups were inoculated with MCF-7-ARO cells at 11 weeks of age. As shown in Figure 1, the mice were either exposed to hormones continuously, or in a treatment mimicking the estrous cycle in the mouse (because we were using a mouse model) or human (because the implanted tumor tissue was of human origin). Throughout the experiments, ovariectomized animals received $0.1 \mathrm{mg}$ dehydroepiandrosterone (DHEA) daily via subcutaneous injection, to allow the aromatization process which is responsible for much of postmenopausal hormone production and which is attacked by aromatase inhibitors. Estrogen (E), progesterone $(\mathrm{P})$, and testosterone $(\mathrm{T})$ were packed in individual silastic tubes. Dosages were adjusted such that they would result in 40 or $100 \mathrm{pg} / \mathrm{ml}$ estradiol, $6 \mathrm{ng} / \mathrm{ml}$ progesterone, and $50 \mathrm{ng} / \mathrm{ml}$ testosterone in circulation. Anastrozole, an aromatase inhibitor, which is used as an adjuvant therapy in postmenopausal breast cancers, was administered via subcutaneous injections (60 $\mu \mathrm{g}$ daily/mouse).

\section{Running wheel experiments}

Mice were housed in groups of 3 animals per cage. A running wheel was placed in the cage of experimental 


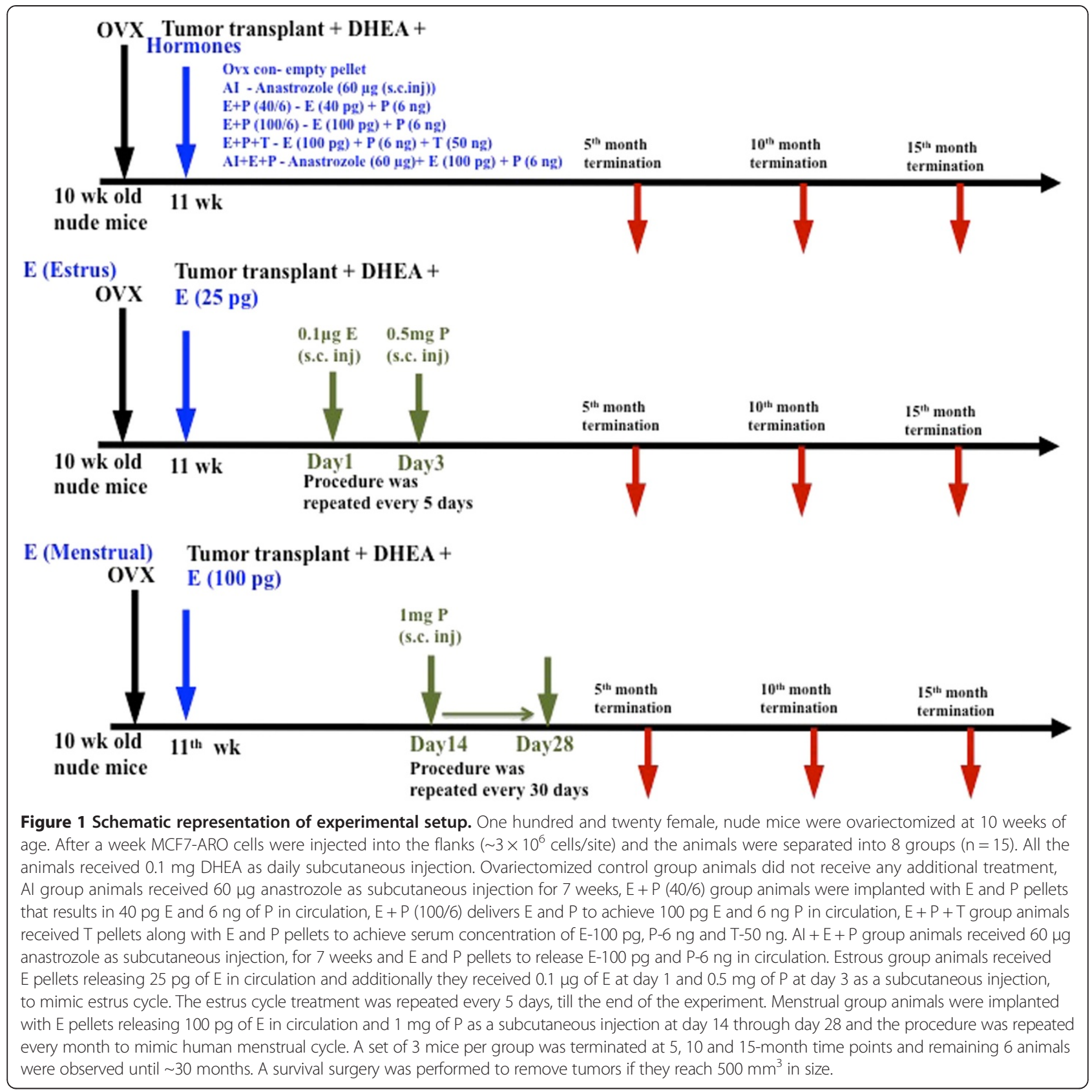

animals to assess voluntary wheel running behavior as a measure of physical activity. The number of revolutions was monitored using a sensor connected to a computer. Because 3 mice were housed per cage, the average number of rotations per hour was calculated based on the total revolutions per hour divided by the number of mice in the cage.

\section{Morris water maze tests}

The Morris water maze was used to measure cognition and the spatial learning ability of the animals [22]. Briefly, the water maze was a circular pool $(120 \mathrm{~cm}$ in diameter,
$40 \mathrm{~cm}$ in height) with water filled to $2 \mathrm{~cm}$ and maintained at a temperature of $20 \pm 2 \mathrm{C}$. A plastic square platform, $14 \mathrm{~cm} 14 \mathrm{~cm}$, was placed $1 \mathrm{~cm}$ below the water level. Each mouse received five training trials $(50$ seconds each) for 7 consecutive days. During the first 2 days, we used a visible platform, but we used a hidden platform for all other days. Latency to escape from the water maze (the time to find the submerged platform) was calculated for each trial within the 50-second period. Swimming distance and speed were also analyzed. The percentage of mice that reached the platform in each group was calculated. 


\section{Serum lipid and lipoprotein analyses}

Animals were euthanized at different time points and serum was separated from whole blood collected and used for biochemical analyses. Serum levels of total cholesterol, free cholesterol, high-density lipoprotein (HDL), low-density lipoprotein (LDL), very-low-density lipoprotein (VLDL), and triglycerides were measured using commercially available kits (Biovision, Milpitas, CA).

\section{Total and bone-specific alkaline phosphatase analyses}

Determination of serum alkaline phosphatase (ALP) levels reflects the bone health of animals [23]. ALP enzymatic activity was quantified using a p-nitrophenylphosphate (pNPP) colorimetric assay kit (Biovision, Milpitas, CA). Serum bone-specific alkaline phosphatase levels were determined using an ELISA kit (Cosmo Bio, Carlsbad, CA).

\section{Statistical analysis}

The data are expressed as mean \pm SEM. The MannWhitney test or Student's t test was used to analyze differences between the groups using the GraphPad Prism 6 software package. Any value that was $P<0.05$ was considered statistically significant.

\section{Results}

\section{Effect of the aromatase inhibitor and hormones on} mammary tumor growth

To mimic the postmenopausal breast cancer condition, tumor xenografts were established using aromataseoverexpressing MCF 7 cells in ovariectomized mice. Tumor xenografts in the control ovariectomized mice were relatively fast growing and reached sizes of $500 \mathrm{~mm}^{3}(8 \mathrm{~mm}$ diameter) 12 weeks after transplantation (Figure 2a). Mice treated with anastrozole showed slower tumor growth during the active phase of treatment (designed to replicate the standard 5-year treatment protocol in women), but growth accelerated upon cessation. AI-treated tumors reached $490 \mathrm{~mm}^{3}$ after 16 weeks. Treatment of the anastrozole group with continuous E $(100 \mathrm{pg} / \mathrm{mL})$ plus $\mathrm{P}$ (6 ng/mL) also showed similar effects on the growth of tumor xenografts $\left(500 \mathrm{~mm}^{3} 16\right.$ weeks after tumor transplantation) (Figure 2a). Combination of $\mathrm{E}(40 \mathrm{pg} / \mathrm{mL})$ and $\mathrm{P}(6 \mathrm{ng} / \mathrm{mL})$, along with estrous levels of hormones treatment, did not markedly influence tumor xenograft growth compared with ovariectomized controls (Figure 2a). Ovariectomized control and estrous levels of hormone treatment group animals reached $\sim 520 \mathrm{~mm}^{3}$ at 13 and 15 weeks respectively, whereas tumor xenografts in $\mathrm{E}$ (40 pg/mL)- plus P (6 ng/mL)-treated animals reached sizes of $\sim 550 \mathrm{~mm}^{3}$ as early as 12 weeks after transplantation (Figure $2 \mathrm{a}$ ).

There was a remarkable reduction in the growth of xenografts in animals that received testosterone in addition to $\mathrm{E}$ and P. Furthermore, animals that received cyclical menstrual levels of hormone treatment also had reduced tumor growth. These tumors were relatively slow growing and reached sizes of $380 \mathrm{~mm}^{3}$ and $420 \mathrm{~mm}^{3} 19$ weeks after xenograft transplantation (Figure $2 \mathrm{a}$ ). Other slow growing tumor xenografts were observed in the $\mathrm{E}(100 \mathrm{pg} / \mathrm{mL})$ plus $\mathrm{P}(6 \mathrm{ng} / \mathrm{mL})$ treatment group, with a latency of 17 weeks to reach a size of $480 \mathrm{~mm}^{3}$ (Figure 2a).

\section{Effect of the aromatase inhibitor and hormones on body weight}

Addition of E (100 pg/mL) plus P (6 ng/mL), along with anastrozole treatment, markedly reduced the body weight gain of mice compared with mice treated with AI alone (approximately 16\% reduction compared with the AI-treated group) (Figure 2b). This outcome was considered positive because as for humans, weight gain postovariectomy results in wide-ranging sequelae in the murine model, with diabetic syndromes and resulting paw and forelimb infection a notable example. Ovariectomized controls and anastrozole-treated animals exhibited maximum body weight gain of all groups, and there were no significant differences between these two groups of mice (Figure 2b). Animals that received estrous levels of $E$ plus $P$ in a cyclic manner had the lowest weight gain. The estrous level of $\mathrm{E}$ plus $\mathrm{P}$ treatment was effective in reducing the final body mass by $31 \%$ compared with ovariectomized control animals (Figure 2b). Ovariectomized mice treated with a combination of E, P, and $\mathrm{T}$ had significantly reduced body weights compared with ovariectomized control mice (Figure 2b). Overall, all hormone treatments reduced the weight gain and final body weight of animals compared with ovariectomized controls and anastrozole-treated mice.

\section{Effect of the aromatase inhibitor and hormones on running wheel performance}

Because physical activity reflects general health and wellness, we also observed the physical activity of the animals. Running wheel revolutions per hour were monitored as an indicator of physical activity. AI-treated mice had reduced numbers of revolutions per hour on the running wheel compared with ovariectomized control mice indicating that AI treatment induces a comparatively sedentary life style. Supplementation of E + P with AI treatment increased the running wheel performance of mice to control ovariectomized levels at 5 and 10 months (Figure 3a, see Additional file 1: Figure S1a). Animals treated with $\mathrm{E}$ (40 pg/mL) plus P (6 ng/mL), E (100 pg/mL) plus P (6 ng/ $\mathrm{mL})$, and $\mathrm{E}$ plus $\mathrm{P}$ plus $\mathrm{T}$ significantly increased running wheel activity compared with control ovariectomized mice (Figure 3a). Cyclic treatment with hormones representing estrous and menstrual cycles also improved running wheel performance compared with ovariectomized mice after 5 and 10 months (Figure 3a, see Additional 

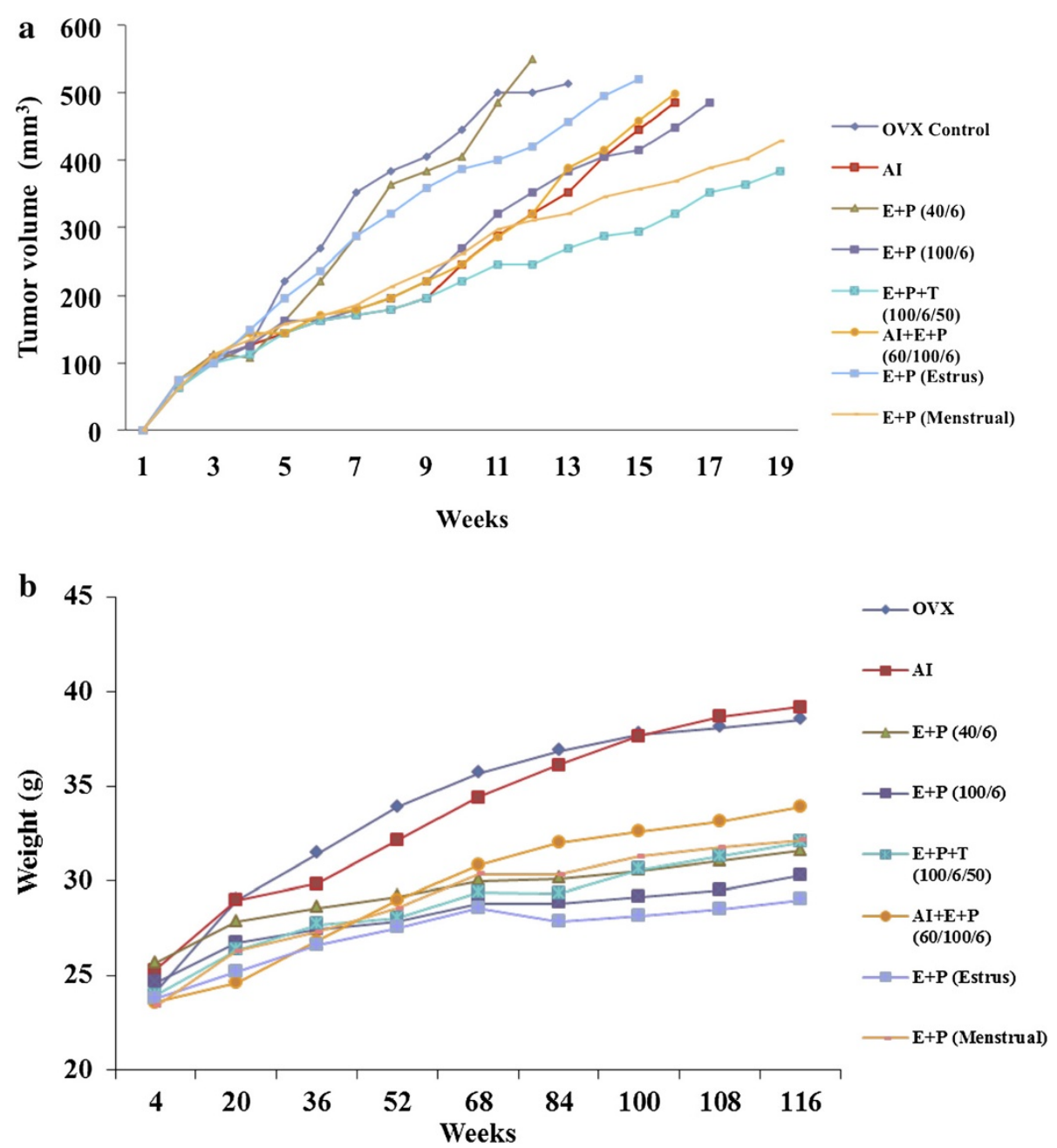

Figure 2 Effect of hormones on MCF7-ARO tumor xenograft growth and body weight in female nude mice. a) Mice were treated with $\mathrm{Al}$ and hormones according to the experimental setup described in Figure 1 in Methods. Tumor growth was measured twice a week and tumor volume was calculated using the formula $4 / 3 r_{1}^{2} r_{2}$, where $r_{1}$ is the minor radius and $r_{2}$ is the major radius. Tumor growth was rapid in ovariectomized control and mice received $\mathrm{E}+\mathrm{P}(40 / 6)$, whereas $\mathrm{E}+\mathrm{P}+\mathrm{T}(100 / 6 / 50)$ and $\mathrm{E}+\mathrm{P}$ (Menstrual) treatment reduced the tumor growth drastically. b) Body weight of the animals shows toxicity of the treatment and general health of the animals. Ovariectomized control and Al treated mice gained weight constantly throughout the experimental period. E + P (Estrus) and E + P (100/6) group animals showed least weight gain compared to other groups. All values are expressed as mean and for the clarity of the bar-diagram the error bars (representing SD) were removed.

file 1: Figure S1). At the 15-month time point, all groups of animals showed similar performance on the running wheel, but with a slight increase in the steady state level of the hormone treatment groups (See Additional file 1: Figure S1b).

\section{Water maze}

To access spatial learning ability, we used water maze experiments. Initially, all animals showed comparatively equal cognitive behavior with 8 to $16 \%$ of animals reaching the platform (Figure 3b). After the trials, mice treated with AI showed the least improvement in spatial learning memory because only $34 \%$ of animals succeeded in reaching the platform whereas $54 \%$ of ovariectomized controls reached the platform (Figure 3b). This finding may indicate that AI reduces cognition and spatial learning ability. Supplementation with E plus P and AI improved cognition and spatial learning ability to $54 \%$ after trials, which showed a positive effective of $\mathrm{E}$ and $\mathrm{P}$ treatment (Figure $3 \mathrm{~b}$ ). The most effective hormone treatment combination was $\mathrm{E}$ plus $\mathrm{P}$ plus $\mathrm{T}$ in steady state and cyclic hormone treatment mimicking estrous cycles, which showed $\sim 80 \%$ improvement in the learning memory of mice (Figure $3 b$ ). Further, approximately $70 \%$ of animals reached the platform in the E $(40 \mathrm{pg} / \mathrm{mL})$ plus $P(6 \mathrm{ng} / \mathrm{mL}), E(100 \mathrm{pg} / \mathrm{mL})$ plus $\mathrm{P}(6 \mathrm{ng} / \mathrm{mL})$, and menstrual levels of hormonetreated groups (Figure $3 \mathrm{~b}$ ). 

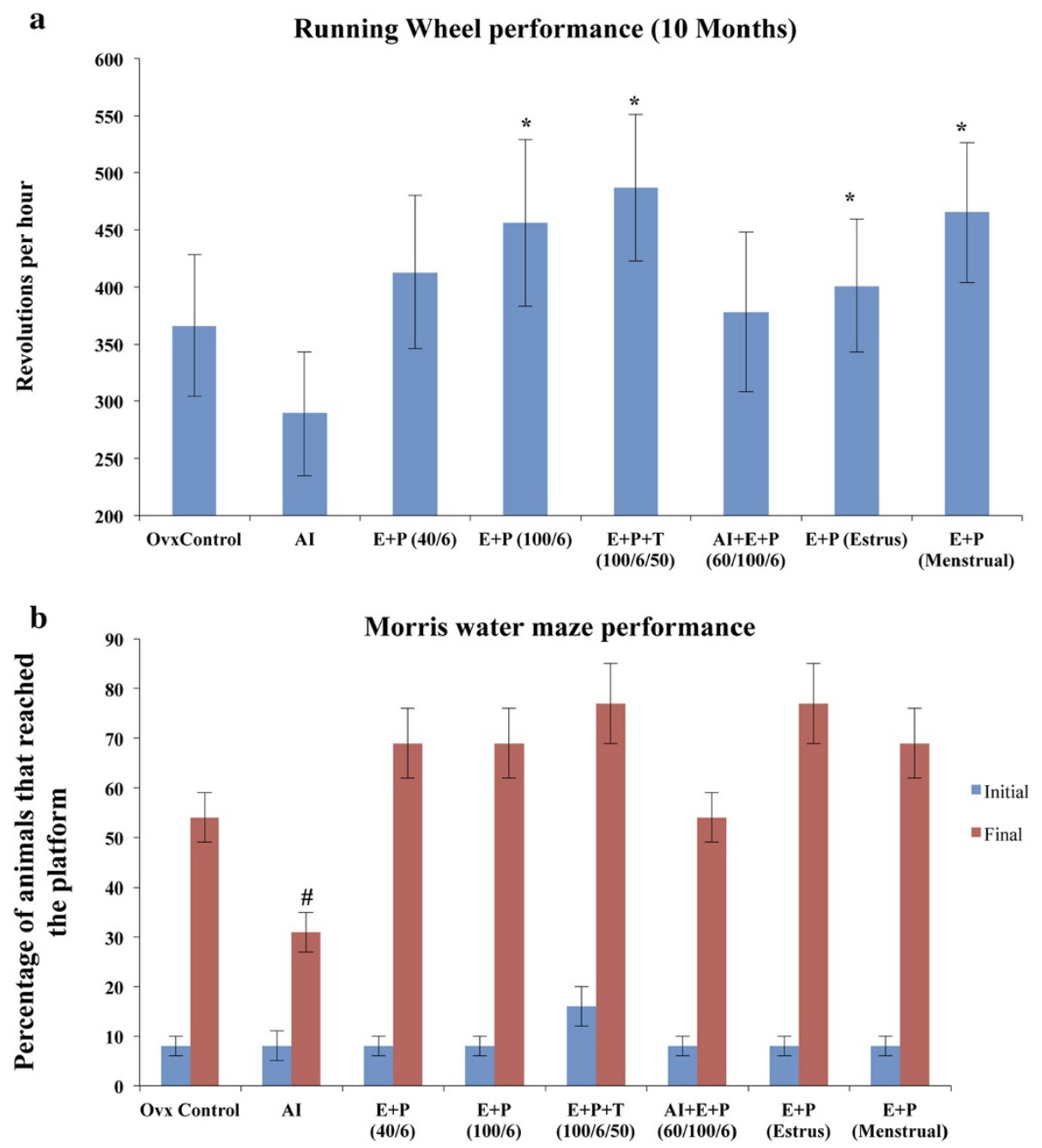

Figure 3 Effect of hormones on physical activity and cognitive skills. a) Voluntary running wheel performance shows the physical activity and desire to perform exercise. Revolutions per hour reflect the average physical activity of the animals. Al treatment showed reduced voluntary physical activity whereas $E+P+T$ treatment showed significantly increased desire towards physical activity. $E+P(100 / 6), E+P$ (Estrus) and E + P (Menstrual) groups also showed significantly improved physical activity compared to Al treated group. $\mathbf{b})$ Cognitive function or spatial learning memory of the mice was tested using Morris water maze. All group mice showed similar cognitive ability during initial training. After training, mice in $\mathrm{Al}$ treatment group showed least improvement and $\mathrm{E}+\mathrm{P}+\mathrm{T}$ group mice showed better cognitive function than other groups. Since, all 5, 10 and 15-month time points showed similar trend, 10-month time point was taken as a representative result. All values are expressed as Mean \pm SD and $p \leq 0.05$ was considered statistically significant. *- represents significant difference between Al treatment and other hormone treatments, \#- represents significant difference between ovariectomized control and Al treatment.

\section{Serum lipids and lipoproteins}

Serum lipid and lipoprotein levels were measured to evaluate the effect of AI and hormone treatments on the cardiovascular health of mice. After 5 and 10 months, serum triglyceride levels were decreased in the AI treatment group compared with the ovariectomized control group. Significant increases in triglyceride levels were observed in $\mathrm{E}(40 \mathrm{pg} / \mathrm{mL})$ plus $\mathrm{P}(6 \mathrm{ng} / \mathrm{mL}), \mathrm{E}(100 \mathrm{pg} / \mathrm{mL})$ plus $\mathrm{P}(6 \mathrm{ng} / \mathrm{mL})$, and the estrous and menstrual cycle levels of hormone treatment groups compared with ovariectomized controls (Figure 4a). After 15 months of hormone exposure, the elevated triglyceride levels returned to the levels in ovariectomized controls in $\mathrm{E}(40 \mathrm{pg} / \mathrm{mL})$ plus $\mathrm{P}$ (6 ng/mL), E (100 pg/mL) plus P (6 ng/mL), and estrous and menstrual cycle levels of hormone treatment groups (See Additional file 2: Figure S2b). The E plus $\mathrm{P}$ plus $\mathrm{T}$ combination treatment showed no difference in triglyceride levels at the 5-, 10-, or 15-month time point (Figure 4a, see Additional file 2: Figure S2a,b). Estimation of free and VLDL/LDL cholesterol levels in serum revealed that AI treatment remarkably increased the levels of these lipids, whereas the addition of E plus P along with AI significantly reduced free cholesterol and VLDL/LDL levels compared with the AI-treated group (Figure $4 \mathrm{~b}, \mathrm{c}$ ). The same trend 


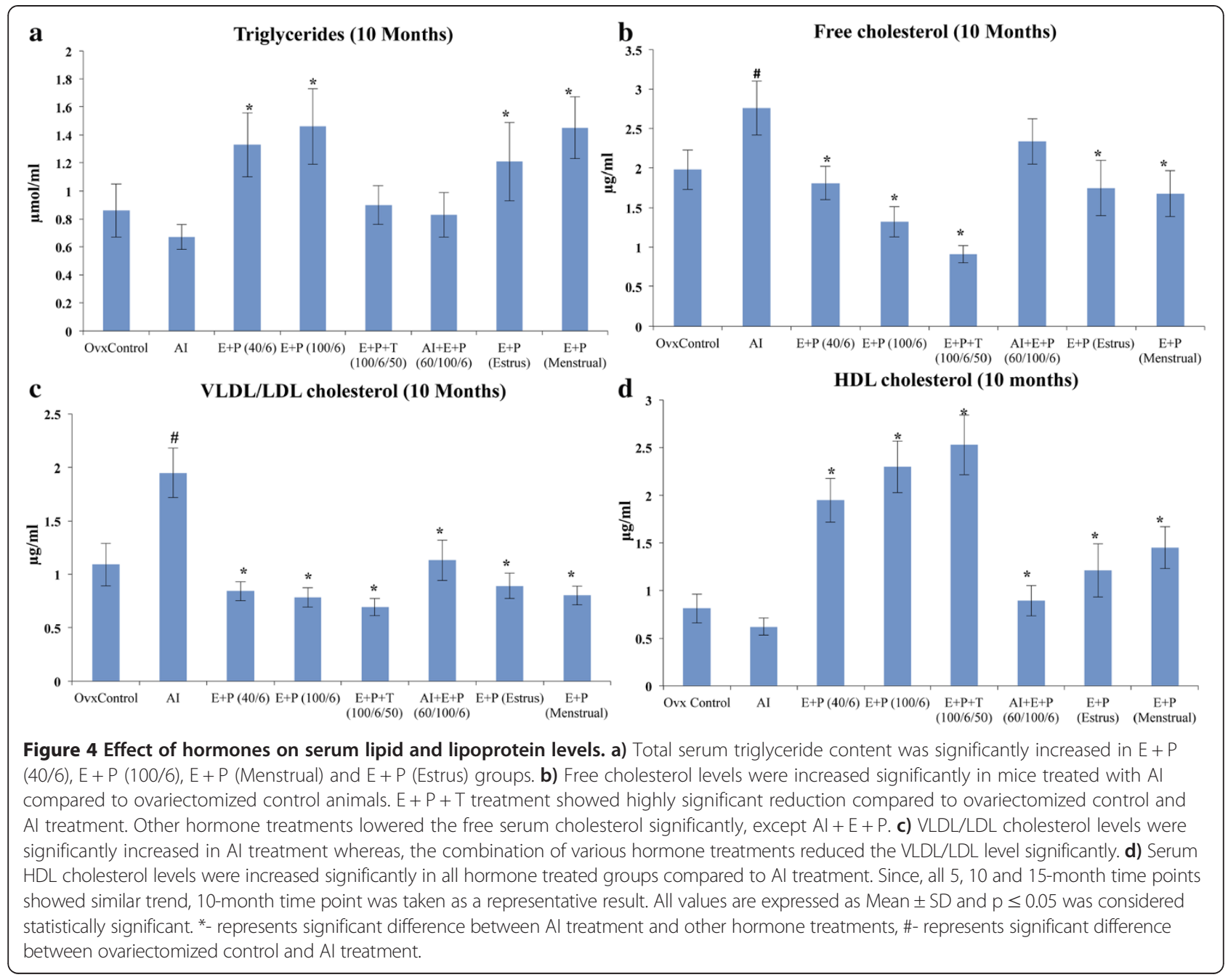

was observed after 5, 10, and 15 months (Figure 4b,c \& see Additional file 3: Figure S3 a-d). The highest reduction in cholesterol levels (both free and VLDL/LDL) was observed in $\mathrm{E}$ plus $\mathrm{P}$ plus $\mathrm{T}$ treatment group. Both menstrual and estrous levels had similar effects on reducing the free and VLDL cholesterol in circulation (Figure 4c \& see Additional file 3: Figure S3 c,d). HDL, the "good cholesterol", was significantly reduced in AI-treated animals after 15 months, indicating an increased risk for cardiovascular diseases (See Additional file 4: Figure S4 b). Combination of $\mathrm{AI}$ and $\mathrm{E}$ plus $\mathrm{P}$ treatment returns the levels of HDL to ovariectomized control levels (Figure 4d \& see Additional file 4: Figure S4 a). Treatment with E plus P plus $\mathrm{T}$ increased serum HDL cholesterol levels compared with ovariectomized controls and could be effective in reducing the risk of cardiovascular diseases (Figure $4 \mathrm{~d} \&$ see Additional file 4: Figure S4 a,b). Both the cyclic levels of hormone treatments increased HDL cholesterol compared with ovariectomized levels after 5 months (See Additional file 4: Figure S4 a). These effects improved and were significant at the 10- and 15-month analyses (Figure $4 \mathrm{~d} \&$ Additional file 4: Figure S4 a,b).

\section{Serum bone formation markers}

Analyses of total ALP levels revealed that there was no marked difference in the activity of total ALP in all groups at each time point (Figure 5a \& see Additional file 5: Figure S5 a,b). Bone-specific ALP activity assays showed a significant reduction in activity in the AI-treated mice (Figure 5b). Because bone-specific ALP is considered a marker for bone formation, our results indicate that AI treatment negatively influences bone formation. The combination of hormones plus AI treatment significantly increased the activity of bone-specific ALP compared with the AI-treated group (Figure $5 \mathrm{~b} \&$ see Additional file 5: Figure S5 c,d). The steady state $[\mathrm{E}(40 \mathrm{pg} / \mathrm{mL})$ plus $\mathrm{P}(6 \mathrm{ng} / \mathrm{mL}), \mathrm{E}(100 \mathrm{pg} / \mathrm{mL})$ plus P $(6 \mathrm{ng} / \mathrm{mL})$, and E plus $\mathrm{P}$ plus $\mathrm{T}]$ and cyclic (estrous and menstrual) hormone treatments showed increased bone-specific ALP activity in serum compared with ovariectomized controls. A similar 

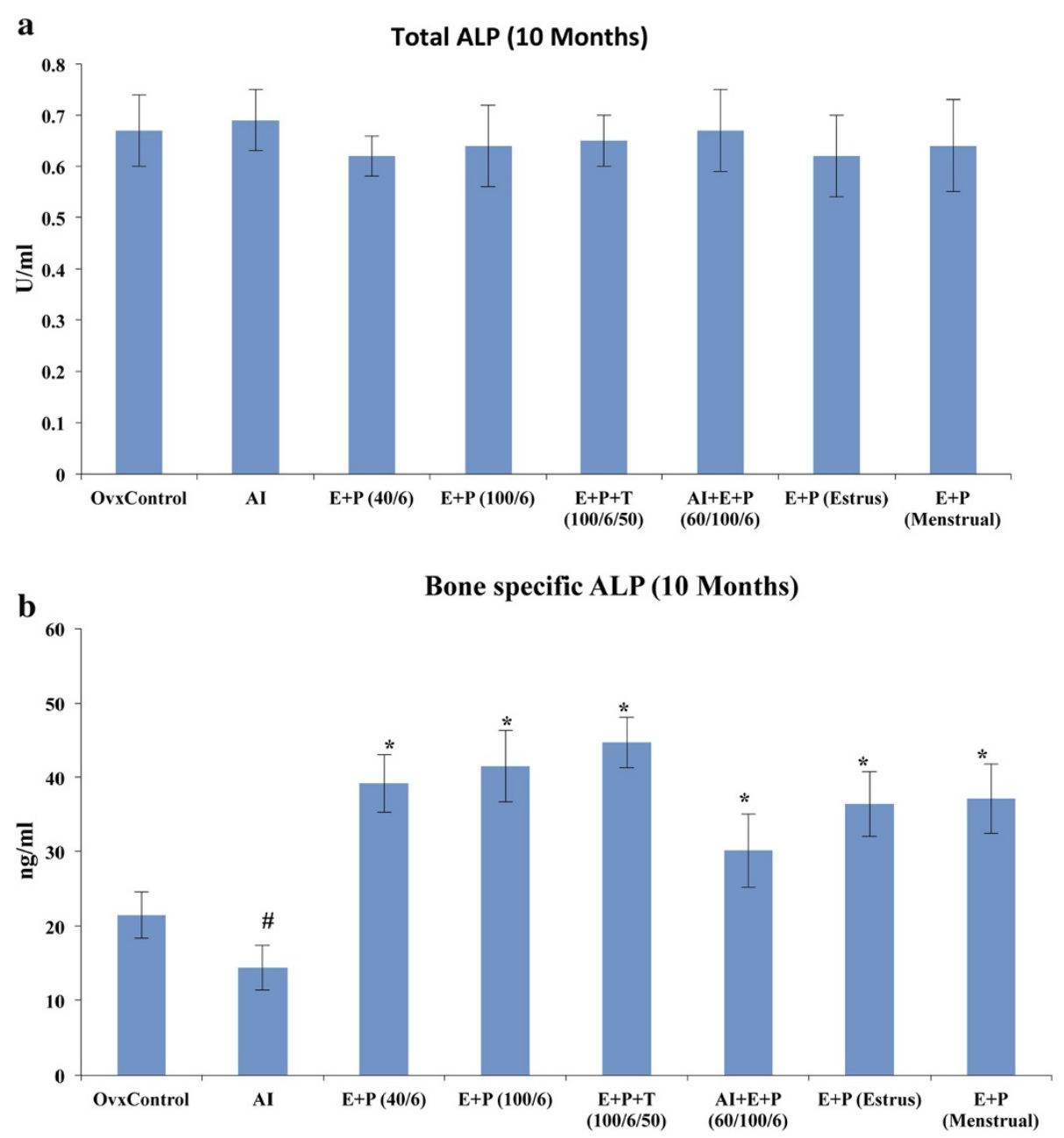

Figure 5 Effect of hormones on total and bone specific alkaline phosphatase (ALP). a) There was no significant change in the level of total ALP was observed at 10 months time point. b) Bone specific ALP levels were increased significantly in combination of hormone treatments. Al treatment reduced the bone specific ALP levels in the serum showing reduced bone formation process. Since, all 5, 10 and 15-month time points showed similar trend, 10-month time point was taken as a representative result. All values are expressed as Mean \pm SD and $p \leq 0.05$ was considered statistically significant. *- represents significant difference between Al treatment and other hormone treatments, \#- represents significant difference between ovariectomized control and Al treatment.

trend was observed at the 5-, 10-, and 15-month time points (Figure 5b \& see Additional file 5: Figure S5 c,d).

\section{Discussion}

Anti-estrogen therapies are currently the standard treatment for estrogen receptor-positive breast cancer recurrence. However, AIs are known to reduce bone mineral density, increasing risk of osteoporosis, and their side effect profile leads to a high discontinuation rate [21].

The current study was performed to investigate hormonal therapeutic regimens that inhibit breast tumor growth without negative effects on cardiovascular and bone formation processes. The ultimate goal of the study was to develop a postmenopausal hormone treatment regimen that blocks the growth of breast cancer while enhancing overall health and quality of life.

The use of hormone replacement therapy for postmenopausal symptoms has been the subject of debate for the past two decades. Studies over that time have revealed a risk-benefit profile that varies by type of hormone, time since menopause, and organ/system in question [24]. In addition, the dose, duration, and mode of administration of hormones are important factors in determining the efficiency and beneficial function of a particular treatment $[25,26]$. However, current standard of practice considers hormones of any type absolutely contraindicated after hormone-receptor-positive breast cancer, with the assumption being that hormones "throw fuel on the fire" of 
cancer. This assumption makes intuitive sense, since current treatment is to block remaining estrogens with aromatase inhibitors, the exact opposite.

Yet hormones have myriad effects throughout the body, effects which influence survival and quality of life as much as breast cancer recurrence does or more. We explored a radical hypothesis: Could an optimal choice of hormones lead to improved survival factors and quality of life enough to outweigh any negative effect on tumor recurrence?

In our experiments, we used steroids in their bioidentical form, as these hormones have been shown to possess a more positive risk-benefit profile than synthetic hormones which have been molecularly altered for patentability or oral bioavailability [27-30]. The first question we sought to address was influence on overall health of an optimal hormone regimen. In the landmark Women's Health Initiative study, a negative risk-benefit profile was seen with oral equine estrogens and oral synthetic medroxyprogesterone acetate (PremPro), a drug combination based on an estrogen formulation first approved in 1942 and which continues to dominate the market in Englishspeaking countries. We therefore chose estradiol and progesterone delivered non-orally, as is commonly used in southern European countries and increasingly in Englishspeaking countries as well, based on an extensive literature indicating more favorable global risk-benefit profile [31]. Our results show that the right combination of hormone treatments is essential to achieving the desired effect on postmenopausal symptoms and the risks associated with osteoporosis and cardiovascular disease (CVD). E plus P plus $\mathrm{T}$ treatment was associated with increased cognition, physical activity, and cardiovascular and bone health in the mouse model, and demonstrates the potential significance of hormone treatment in postmenopausal women. Testosterone is critical to both physical activity and mental health. Testosterone has been shown to be beneficial to cognitive function and memory. It also functions like vasodilator and enhances endothelial functions to improve cardiac health $[32,33]$. In our study we found that addition of testosterone along with estradiol and progesterone improves the cognitive function, physical activity and cardiac health. In agreement with our study, testosterone therapy has also been shown to reduce breast cancer incidence in postmenopausal women and breast tumor growth in animal models [34-37].

Because estrogen-blocking aromatase inhibitors are the current adjuvant treatment after hormone-sensitive breast cancer, common sense would lead to the assumption that any treatment containing estrogen itself would lead to opposite, highly negative impact on tumor growth. However, this turned out not to be the case. As was the case for general health markers, maximal reduction in tumor growth was achieved by E plus $\mathrm{P}$ plus $\mathrm{T}$ treatment. In only one group, the lowest-dose $\mathrm{E}$ plus $\mathrm{P}$ group, did addition of estrogen result in tumor volumes slightly worse than control. Our results thus did not confirm the "throwing fuel on the fire" conception prevalent among clinicians.

Furthermore, the antitumor effect of AI treatment, though notable when compared to control, did not excel when compared to hormone treatment. Treatment with AI had initial antitumor activity, consistent with the results of preclinical studies leading to the approval of AIs. However, three of five hormone treatment regimens provided similar suppression of tumor volume to the AI regimen. And with cessation of the AI treatment phase (chosen to be equivalent to the current clinical standard of care, 5 years), the antitumor effect of AIs diminished, leading to a steepened rise in tumor volume, while the most effective hormone regimens, including $\mathrm{E}$ plus $\mathrm{P}$ plus $\mathrm{T}$, continued to more effectively suppress tumor volume.

A frequent criticism of studies in a mouse model is that they may have limited utility in predicting eventual clinical outcomes. Anticipating this objection, we designed our study to exactly mimic conditions such as dose and length of treatment used in pre-approval studies of anastrozole (Arimidex ${ }^{\odot}$ ), a leading aromatase inhibitor currently on the market. These murine-model results were seen to accurately predict outcomes later seen in large clinical trials such as the ATAC (Arimidex, Tamoxifen, Alone or in Combination) trial and were part of the basis for approval of anastrozole [38,39].

Although an E plus P plus T regimen performed better in our study than AIs (the current standard of care) on measures of both tumor growth and general health, considerable momentum, as well as market forces, works against a reversal in treatment practice from hormone inhibitors to hormones. We therefore sought to determine whether addition of optimal hormones could improve quality of life and general health indicators when added to-instead of substituting for-AI treatment, without worsening tumor outcomes. Our results indicated the viability of this approach. When added to AIs, estradiol and progesterone significantly improved the general health of the animals as measured by cardiac and bone health markers (although positive impact of hormones on cardiac and bone health markers was not as marked when added to AIs as when used alone), without promoting breast tumor growth. We discuss possible explanations for this seeming paradox-improved general health but lack of tumor stimulation-below.

Aromatase classically converts C19 steroids (androgens) to C18 steroids (estrogens) with the addition of a hydroxyl group. Because it has a wide range of substrate specificity, it accepts DHEA as a substrate and converts it to estrogens $[40,41]$. Estrogen, which is predominantly produced in postmenopausal women by the aromatization of DHEA, selectively activates ER $\alpha[42,43]$. Aromatase has 
high expression in breast tumor cells and the surrounding stroma in postmenopausal women $[44,45]$. Als inhibit aromatase and reduce the conversion of androgens to estrogens in postmenopausal breast cancer patients.

However, this inhibition is not reliably effective longterm because many patients develop resistance to AI treatment [46-48]. Furthermore, inhibiting aromatase in tissues outside the breast is associated with a variety of negative sequelae in joints, bone, and other tissues [49-53]. Our data indicate that an optimal dose of estradiol and progesterone can overcome effects on bone, cardiovascular, and cognitive health. Furthermore, the addition of testosterone along with estradiol and progesterone enhances the beneficial effects.

Large observational studies suggest estrogens have a cardioprotective effect $[13,54,55]$. Abnormal serum lipid levels have been associated with an increased risk for CVDs $[13,54]$. Low HDL and high LDL levels in serum are mainly attributed to an increased risk of CVDs. Several clinical and experimental studies indicate that estradiol treatment is beneficial to the heart by reducing LDL levels and increasing HDL levels in circulation [56-58]. Based on epidemiological studies, CVDs are prevalent in postmenopausal women, and serum concentrations of estrogen are inversely associated with CVD risk [59]. Estrogen replacement therapy initiated within 5 years after menopause has a beneficial effect on cardiovascular risk factors, but not if the therapy is begun later [60]. Natural hormone 17-b estradiol was more effective in reducing CVD risk factors than conjugated equine estrogens, and it is also affected by an oral or transdermal route of delivery [61]. Taking all of these factors into account, the cellular mechanism of estradiol-induced cardioprotection involves the contribution of several factors including time of administration, type of hormone administered, and mode of administration. Our data demonstrate that administration of hormones immediately after ovariectomy results in improved cardiac health, in agreement with data from clinical studies.

The role of progesterone versus synthetic progestins in cardiovascular health is the subject of much debate. The WHI study demonstrated increased atherosclerosis upon the use of synthetic progestins $[13,62,63]$. In a long-term randomized study that accessed and compared the effects of synthetic progestins and progesterone on serum lipids, synthetic progestins negatively influenced the beneficial effect of estrogens by lowering serum HDL levels [55]. Progesterone, in contrast, has been shown to support the cardioprotective actions of estrogen in several other studies [64-70]. Our results indicate that estrogen and progesterone improve the serum lipid profile and reduce the risk of CVDs in a postmenopausal breast cancer mouse model.

Osteoporosis is a major concern in postmenopausal women. Several studies have shown that estradiol increases bone formation and prevents osteoporosis [71,72]. Similarly, depletion of estrogen resulted in osteoporosis, supporting the notion that estrogens are important for bone formation $[73,74]$. Clinical studies have indicated that progesterone treatment helps maintain bone mass [75-77]. Progesterone supports bone formation by preventing glucocorticoid-induced bone loss [54]. Several animal and human studies have demonstrated progesterone's positive effect on bone formation as well as inhibition of bone resorption [76-78]. Studies evaluating estrogen and progesterone supplementation suggest estrogen and progesterone have distinct but complementary roles in bone maintenance [75-77,79]. The addition of testosterone positively influences bone mass by preventing urinary calcium loss. Our findings demonstrate that the addition of hormones along with AI treatment is beneficial for bone health in postmenopausal women.

Our data on physical activity, cognition, and spatial learning clearly demonstrate the importance of hormones in addition to AIs for breast cancer treatment. Cyclical administration of hormones appears to have a slightly better effect versus administration of steady levels of hormones. It is interesting that the addition of testosterone has a significant positive impact on all aspects that were studied in this investigation.

\section{Conclusions}

In summary, our results indicate that the use of appropriate combinations of natural hormones along with, or instead of, classical breast cancer treatments is beneficial against postmenopausal symptoms and improves cardiac and osteoporotic health in the mouse model. The natural hormone combinations tested in this study provide evidence for a better alternative to standard aromatase inhibitor treatment following breast cancer in women.

\section{Additional files}

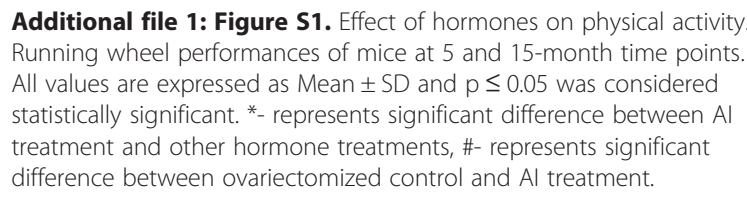

Additional file 1: Figure S1. Effect of hormones on physical activity. Running wheel performances of mice at 5 and 15 -month time points. All values are expressed as Mean \pm SD and $p \leq 0.05$ was considered statistically significant. *- represents significant difference between Al treatment and other hormone treatments, \#- represents significant difference between ovariectomized control and Al treatment.

Additional file 2: Figure S2. Effect of hormone treatments on serum triglycerides. Serum triglycerides levels at 5-month time point showed similar trends compared to 10 -month time point. At $15^{\text {th }}$ month the level of triglycerides were similar in all the groups. All values are expressed as Mean \pm SD and $p \leq 0.05$ was considered statistically significant. *- represents significant difference between Al treatment and other hormone treatments, \#- represents significant difference between ovariectomized control and Al treatment.

Additional file 3: Figure S3. Effect of hormone treatments on serum free cholesterol and VLDL/LDL cholesterol. The level of free cholesterol was reduced in the $E+P(100 / 6), E+P+T, E+P$ (Menstrual) and $E+P$ (Estrus) groups in both 5 and 15 month time points. *- represents significant difference between Al treatment and other hormone treatments, 
\#- represents significant difference between ovariectomized control and A treatment.

Additional file 4: Figure S4. Effect of hormone treatments on serum $\mathrm{HDL}$ cholesterol. The level of free cholesterol was reduced in the $\mathrm{Al}$ treatment but increased in other hormone treatments in both 5 and 15-month time points. *- represents significant difference between Al treatment and other hormone treatments, \#- represents significant difference between ovariectomized control and Al treatment.

Additional file 5: Figure S5. Effect of hormones on total and bone specific ALP. Levels of ALP in all the groups were similar in all the time points. Bone specific ALP levels were increased in all the hormone treated groups. *- represents significant difference between Al treatment and other hormone treatments, \#- represents significant difference between ovariectomized control and Al treatment.

\section{Abbreviations}

Al: Aromatase inhibitor; ALP: Alkaline phosphatase; ATAC: Arimidex; Tamoxifen: Alone or in Combination; CVD: Cardiovascular disease; DHEA: Dehydroepiandrosterone; E: Estrogen; HDL: High density lipoprotein; HRT: Hormone replacement therapy; LDL: Low density lipoprotein; P: Progesterone; T: Testosterone; VLDL: Very low density lipoprotein; WHI: Women's health initiative.

\section{Competing interests}

The authors declare that they have no competing interests.

\section{Authors' contributions}

$\mathrm{RL}$ designed the study, carried out the experiments, supervised the project and prepared the manuscript. AA carried out the experiments, collected and analyzed the data. EL conceived of the study, participated in study design, and was involved in manuscript preparation. All authors read and approved the final manuscript.

\section{Acknowledgements}

This work was funded by a grant from Parsemus Foundation. We thank Dr. Linda Brent for her help with reviewing the manuscript.

\section{Author details}

${ }^{1}$ Center of Excellence in Cancer Research, Department of Biomedical Sciences, Paul L. Foster School of Medicine, Texas Tech University Health Sciences Center, El Paso, Texas 79905, USA. ${ }^{2}$ Parsemus Foundation, Berkeley, California 94702, USA.

Received: 4 April 2014 Accepted: 17 June 2014

Published: 15 July 2014

\section{References}

1. Bray F, Ren JS, Masuyer E, Ferlay J: Global estimates of cancer prevalence for 27 sites in the adult population in 2008. Int J Cancer 2013, 132(5):1133-1145.

2. Siegel R, Naishadham D, Jemal A: Cancer statistics, 2012. CA Cancer J Clin 2012, 62(1):10-29.

3. Howlader N, Altekruse SF, Li Cl, Chen WW, Clarke CA, Ries LA, Cronin KA: US Incidence of Breast Cancer Subtypes Defined by Joint Hormone Receptor and HER2 Status. J Nat/ Cancer Inst 2014, 106:5. doi:10.1093/jnci/dju055.

4. Nilas L, Christiansen C: Bone mass and its relationship to age and the menopause. J Clin Endocrinol Metab 1987, 65(4):697-702.

5. Barrett-Connor E, Bush TL: Estrogen and coronary heart disease in women. JAMA 1991, 265(14):1861-1867.

6. Gambrell RD Jr, Teran AZ: Changes in lipids and lipoproteins with long-term estrogen deficiency and hormone replacement therapy. Am J Obstet Gynecol 1991, 165(2):307-315. discussion 315-317.

7. Stampfer MJ, Colditz GA, Willett WC, Manson JE, Rosner B, Speizer FE, Hennekens $\mathrm{CH}$ : Postmenopausal estrogen therapy and cardiovascular disease, Ten-year follow-up from the nurses' health study. N Engl J Med 1991, 325(11):756-762.

8. Coope J, Thomson JM, Poller L: Effects of "natural oestrogen" replacement therapy on menopausal symptoms and blood clotting. Br Med J 1975, 4(5989):139-143.
9. Lobo RA: Ovarian hyperandrogenism and androgen-producing tumors. Endocrinol Metab Clin North Am 1991, 20(4):773-805.

10. Limouzin-Lamothe MA, Mairon N, Joyce CR, Le Gal M: Quality of life after the menopause: influence of hormonal replacement therapy. Am J Obstet Gynecol 1994, 170(2):618-624

11. Cauley JA, Seeley DG, Ensrud K, Ettinger B, Black D, Cummings SR: Estrogen replacement therapy and fractures in older women, Study of Osteoporotic Fractures Research Group. Ann Intern Med 1995, 122(1):9-16.

12. Chlebowski RT, Anderson GL: Changing concepts: Menopausal hormone therapy and breast cancer. J Natl Cancer Inst 2012, 104(7):517-527.

13. Rossouw JE, Anderson GL, Prentice RL, LaCroix AZ, Kooperberg C, Stefanick ML, Jackson RD, Beresford SA, Howard BV, Johnson KC, Kotchen JM, Ockene J, Writing Group for the Women's Health Initiative Investigators: Risks and benefits of estrogen plus progestin in healthy postmenopausal women: principal results From the Women's Health Initiative randomized controlled trial. JAMA 2002, 288(3):321-333.

14. Bentrem DJ, Jordan VC: Targeted antiestrogens for the prevention of breast cancer. Oncol Res 1999, 11(9):401-407.

15. Jordan VC: Chemoprevention in the 21 st century: is a balance best or should women have no estrogen at all? J Clin Oncol 2005, 23(8):1598-1600

16. Uray IP, Brown PH: Prevention of breast cancer: current state of the science and future opportunities. Expert Opin Investig Drugs 2006, 15(12):1583-1600.

17. Di Prospero LS, Seminsky M, Honeyford J, Doan B, Franssen E, Meschino W, Chart $\mathrm{P}$, Warner E: Psychosocial issues following a positive result of genetic testing for BRCA1 and BRCA2 mutations: findings from a focus group and a needs-assessment survey. CMAJ 2001, 164(7):1005-1009.

18. MacMahon B, Cole P, Lin TM, Lowe CR, Mirra AP, Ravnihar B, Salber EJ, Valaoras VG, Yuasa S: Age at first birth and breast cancer risk. Bull World Health Organ 1970, 43(2):209-221.

19. Pandya N, Morris GJ: Toxicity of aromatase inhibitors. Semin Oncol 2006, 33(6):688-695

20. Aydiner A: Meta-analysis of breast cancer outcome and toxicity in adjuvant trials of aromatase inhibitors in postmenopausal women. Breast 2013, 22(2):121-129.

21. Hershman DL, Kushi LH, Shao T, Buono D, Kershenbaum A, Tsai WY, Fehrenbacher L, Gomez SL, Miles S, Neugut Al: Early discontinuation and nonadherence to adjuvant hormonal therapy in a cohort of 8,769 early-stage breast cancer patients. J Clin Oncol 2010, 28(27):4120-4128.

22. Li L, Ding J, Marshall C, Gao J, Hu G, Xiao M: Pretraining affects Morris water maze performance with different patterns between control and ovariectomized plus D-galactose-injected mice. Behav Brain Res 2011, 217(1):244-247.

23. Eastell R, Hannon RA: Biomarkers of bone health and osteoporosis risk Proc Nutr Soc 2008, 67(2):157-162

24. Goodman MP: Are all estrogens created equal? A review of oral vs. transdermal therapy. J Womens Health (Larchmt) 2012, 21(2):161-169.

25. Stanosz S, Zochowska E, Safranow K, Sieja K, Stanosz M: Influence of modified transdermal hormone replacement therapy on the concentrations of hormones, growth factors, and bone mineral density in women with osteopenia. Metabolism 2009, 58(1):1-7.

26. Davey DA: Update: estrogen and estrogen plus progestin therapy in the care of women at and after the menopause. Womens Health (Lond Engl) 2012, 8(2):169-189.

27. Maki PM: Minireview: effects of different $\mathrm{HT}$ formulations on cognition. Endocrinology 2012, 153(8):3564-3570.

28. Mueck AO: Postmenopausal hormone replacement therapy and cardiovascular disease: the value of transdermal estradiol and micronized progesterone. Climacteric 2012, 15(Suppl 1):11-17.

29. Archer DF, Oger E: Estrogen and progestogen effect on venous thromboembolism in menopausal women. Climacteric 2012, 15(3):235-240

30. Canonico M, Plu-Bureau G, Scarabin PY: Progestogens and venous thromboembolism among postmenopausal women using hormone therapy. Maturitas 2011, 70(4):354-360.

31. Simon JA: What's new in hormone replacement therapy: focus on transdermal estradiol and micronized progesterone. Climacteric 2012, 15(Suppl 1):3-10.

32. Davison S, Thipphawong J, Blanchard J, Liu K, Morishige R, Gonda I, Okikawa J, Adams J, Evans A, Otulana B, Davis S: Pharmacokinetics and 
acute safety of inhaled testosterone in postmenopausal women. J Clin Pharmacol 2005, 45(2):177-184.

33. Montalcini T, Gorgone G, Gazzaruso C, Sesti G, Perticone F, Pujia A: Endogenous testosterone and endothelial function in postmenopausal women. Coron Artery Dis 2007, 18(1):9-13.

34. Pike CJ, Carroll JC, Rosario ER, Barron AM: Protective actions of sex steroid hormones in Alzheimer's disease. Front Neuroendocrinol 2009, 30(2):239-258.

35. Glaser RL, Dimitrakakis C: Reduced breast cancer incidence in women treated with subcutaneous testosterone, or testosterone with anastrozole: a prospective, observational study. Maturitas 2013, 76(4):342-349.

36. Dimitrakakis C, Zava D, Marinopoulos S, Tsigginou A, Antsaklis A, Glaser R: Low salivary testosterone levels in patients with breast cancer. BMC Cancer 2010, 10:547. -10-547

37. Farhat GN, Cummings SR, Chlebowski RT, Parimi N, Cauley JA, Rohan TE, Huang AJ, Vitolins M, Hubbell FA, Manson JE, Cochrane BB, Lane DS, Lee JS: Sex hormone levels and risks of estrogen receptor-negative and estrogen receptor-positive breast cancers. J Natl Cancer Inst 2011, 103(7):562-570.

38. Yue W, Zhou D, Chen S, Brodie A: A new nude mouse model for postmenopausal breast cancer using MCF-7 cells transfected with the human aromatase gene. Cancer Res 1994, 54(19):5092-5095.

39. Brodie AH, Jelovac D, Long B: The intratumoral aromatase model: studies with aromatase inhibitors and antiestrogens. J Steroid Biochem Mol Biol 2003, 86(3-5):283-288.

40. Simpson ER, Mahendroo MS, Means GD, Kilgore MW, Hinshelwood MM, Graham-Lorence S, Amarneh B, Ito Y, Fisher CR, Michael MD: Aromatase cytochrome P450, the enzyme responsible for estrogen biosynthesis. Endocr Rev 1994, 15(3):342-355.

41. Kellis JT Jr, Vickery LE: Purification and characterization of human placental aromatase cytochrome P-450. J Biol Chem 1987, 262(9):4413-4420.

42. Rich RL, Hoth LR, Geoghegan KF, Brown TA, LeMotte PK, Simons SP, Hensley $P$, Myszka DG: Kinetic analysis of estrogen receptor/ligand interactions. Proc Natl Acad Sci U S A 2002, 99(13):8562-8567.

43. Zhu BT, Han GZ, Shim JY, Wen Y, Jiang XR: Quantitative structure-activity relationship of various endogenous estrogen metabolites for human estrogen receptor alpha and beta subtypes: Insights into the structural determinants favoring a differential subtype binding. Endocrinology 2006, 147(9):4132-4150.

44. O'Neill JS, Elton RA, Miller WR: Aromatase activity in adipose tissue from breast quadrants: a link with tumour site. Br Med J (Clin Res Ed) 1988, 296(6624):741-743.

45. Bulun SE, Price TM, Aitken J, Mahendroo MS, Simpson ER: A link between breast cancer and local estrogen biosynthesis suggested by quantification of breast adipose tissue aromatase cytochrome P450 transcripts using competitive polymerase chain reaction after reverse transcription. J Clin Endocrinol Metab 1993, 77(6):1622-1628.

46. Sabnis GJ, Jelovac D, Long B, Brodie A: The role of growth factor receptor pathways in human breast cancer cells adapted to long-term estrogen deprivation. Cancer Res 2005, 65(9):3903-3910.

47. Jelovac D, Sabnis G, Long BJ, Macedo L, Goloubeva OG, Brodie AM: Activation of mitogen-activated protein kinase in xenografts and cells during prolonged treatment with aromatase inhibitor letrozole. Cancer Res 2005, 65(12):5380-5389.

48. Jelovac D, Macedo L, Goloubeva OG, Handratta V, Brodie AM: Additive antitumor effect of aromatase inhibitor letrozole and antiestrogen fulvestrant in a postmenopausal breast cancer model. Cancer Res 2005, 65(12):5439-5444.

49. Eastell R, Adams JE, Coleman RE, Howell A, Hannon RA, Cuzick J, Mackey JR, Beckmann MW, Clack G: Effect of anastrozole on bone mineral density: 5 -year results from the anastrozole, tamoxifen, alone or in combination trial 18233230. J Clin Oncol 2008, 26(7):1051-1057.

50. Sestak I, Sapunar F, Cuzick J: Aromatase inhibitor-induced carpal tunnel syndrome: results from the ATAC trial. J Clin Oncol 2009, 27(30):4961-4965

51. Cuzick J, Sestak I, Cella D, Fallowfield L, ATAC Trialists' Group: Treatment-emergent endocrine symptoms and the risk of breast cancer recurrence: a retrospective analysis of the ATAC trial. Lancet Oncol 2008, 9(12):1143-1148.

52. Cuzick J, Sestak I, Baum M, Buzdar A, Howell A, Dowsett M, Forbes JF, ATAC/LATTE investigators: Effect of anastrozole and tamoxifen as adjuvant treatment for early-stage breast cancer: 10-year analysis of the ATAC trial. Lancet Oncol 2010, 11(12):1135-1141.

53. Tannock IF: 10-year analysis of the ATAC trial: wrong conclusion? Lancet Oncol 2011, 12(3):216-217. author reply 217.

54. Salpeter SR, Walsh JM, Ormiston TM, Greyber E, Buckley NS, Salpeter EE: Meta-analysis: effect of hormone-replacement therapy on components of the metabolic syndrome in postmenopausal women. Diabetes Obes Metab 2006, 8(5):538-554.

55. The Writing Group for the PEPI Trial: Effects of estrogen or estrogen/ progestin regimens on heart disease risk factors in postmenopausal women. The Postmenopausal Estrogen/Progestin Interventions (PEPI) Trial. JAMA 1995, 273(3):199-208.

56. Godsland IF, Winkler U, Lidegaard O, Crook D: Occlusive vascular diseases in oral contraceptive users. Epidemiology, pathology and mechanisms. Drugs 2000, 60(4):721-869.

57. Godsland IF, Manassiev NA, Felton CV, Proudler AJ, Crook D, Whitehead MI Stevenson JC: Effects of low and high dose oestradiol and dydrogesterone therapy on insulin and lipoprotein metabolism in healthy postmenopausal women. Clin Endocrinol (Oxf) 2004, 60(5):541-549.

58. Godsland IF: Biology: risk factor modification by OCs and HRT lipids and lipoproteins. Maturitas 2004, 47(4):299-303.

59. Go AS, Mozaffarian D, Roger VL, Benjamin EJ, Berry JD, Borden WB, Bravata DM, Dai S, Ford ES, Fox CS, Franco S, Fullerton HJ, Gillespie C, Hailpern SM, Heit JA, Howard VJ, Huffman MD, Kissela BM, Kittner SJ, Lackland DT, Lichtman JH, Lisabeth LD, Magid D, Marcus GM, Marelli A, Matchar DB, McGuire DK, Mohler ER, Moy CS, Mussolino ME, et al: Heart disease and stroke statistics-2013 update: a report from the American Heart Association. Circulation 2013, 127(1):e6-e245.

60. Howard BV, Rossouw JE: Estrogens and cardiovascular disease risk revisited the Women's Health Initiative. Curr Opin Lipidol 2013, 24(6):493-499.

61. Bhavnani BR, Stanczyk FZ: Pharmacology of conjugated equine estrogens: Efficacy, safety and mechanism of action. J Steroid Biochem Mol Biol 2014, 142:16-29.

62. Anderson $G L$, Limacher M, Assaf AR, Bassford T, Beresford SA, Black H, Bonds D, Brunner R, Brzyski R, Caan B, Chlebowski R, Curb D, Gass M, Hays J, Heiss G, Hendrix S, Howard BV, Hsia J, Hubbell A, Jackson R, Johnson KC, Judd H, Kotchen JM, Kuller L, LaCroix AZ, Lane D, Langer RD, Lasser N, Lewis CE, Manson J, et al: Effects of conjugated equine estrogen in postmenopausal women with hysterectomy: the Women's Health Initiative randomized controlled trial. JAMA 2004, 291(14):1701-1712.

63. Chlebowski RT, Hendrix SL, Langer RD, Stefanick ML, Gass M, Lane D, Rodabough RJ, Gilligan MA, Cyr MG, Thomson CA, Khandekar J, Petrovitch H, McTiernan A, WHI Investigators: Influence of estrogen plus progestin on breast cancer and mammography in healthy postmenopausal women: the Women's Health Initiative Randomized Trial. JAMA 2003, 289(24):3243-3253.

64. Ottosson UB, Johansson BG, von Schoultz B: Subfractions of high-density lipoprotein cholesterol during estrogen replacement therapy: a comparison between progestogens and natural progesterone. Am J Obstet Gynecol 1985, 151(6):746-750.

65. Minshall RD, Stanczyk FZ, Miyagawa K, Uchida B, Axthelm M, Novy M, Hermsmeyer K: Ovarian steroid protection against coronary artery hyperreactivity in rhesus monkeys. J Clin Endocrinol Metab 1998, 83(2):649-659.

66. Mishra RG, Hermsmeyer RK, Miyagawa K, Sarrel P, Uchida B, Stanczyk FZ, Burry KA, Illingworth DR, Nordt FJ: Medroxyprogesterone acetate and dihydrotestosterone induce coronary hyperreactivity in intact male rhesus monkeys. J Clin Endocrinol Metab 2005, 90(6):3706-3714.

67. Miyagawa K, Rosch J, Stanczyk F, Hermsmeyer K: Medroxyprogesterone interferes with ovarian steroid protection against coronary vasospasm. Nat Med 1997, 3(3):324-327.

68. Saarikoski S, Yliskoski M, Penttila I: Sequential use of norethisterone and natural progesterone in pre-menopausal bleeding disorders. Maturitas 1990, 12(2):89-97.

69. Fahraeus L, Larsson-Cohn U, Wallentin L: L-norgestrel and progesterone have different influences on plasma lipoproteins. Eur J Clin Invest 1983, 13(6):447-453.

70. Ottosson UB: Oral progesterone and estrogen/progestogen therapy. Effects of natural and synthetic hormones on subfractions of HDL cholesterol and liver proteins. Acta Obstet Gynecol Scand Suppl 1984, 127:1-37.

71. Nelson HD: Menopause. Lancet 2008, 371(9614):760-770. 
72. Ebeling PR: Clinical practice, Osteoporosis in men. N Engl J Med 2008, 358(14):1474-1482.

73. Harada S, Rodan GA: Control of osteoblast function and regulation of bone mass. Nature 2003, 423(6937):349-355.

74. Harman SM: Estrogen replacement in menopausal women: recent and current prospective studies, the WHI and the KEEPS. Gend Med 2006, 3(4):254-269.

75. Christiansen C, Riis BJ, Nilas L, Rodbro P, Deftos L: Uncoupling of bone formation and resorption by combined oestrogen and progestagen therapy in postmenopausal osteoporosis. Lancet 1985, 2(8459):800-801.

76. Tremollieres F, Pouilles JM, Ribot C: Effect of long-term administration of progestogen on post-menopausal bone loss: result of a two-year, controlled randomized study. Clin Endocrinol (Oxf) 1993, 38(6):627-631.

77. Tremollieres FA, Pouilles JM, Ribot C: Withdrawal of hormone replacement therapy is associated with significant vertebral bone loss in postmenopausal women. Osteoporos Int 2001, 12(5):385-390.

78. Seifert-Klauss V, Schmidmayr M, Hobmaier E, Wimmer T: Progesterone and bone: a closer link than previously realized. Climacteric 2012, 15(Suppl 1):26-31.

79. Prior JC: Progesterone as a bone-trophic hormone. Endocr Rev 1990, 11(2):386-398

doi:10.1186/1477-7827-12-66

Cite this article as: Arumugam et al:: The role of hormones and aromatase inhibitors on breast tumor growth and general health in a postmenopausal mouse model. Reproductive Biology and Endocrinology 2014 12:66.

\section{Submit your next manuscript to BioMed Central and take full advantage of:}

- Convenient online submission

- Thorough peer review

- No space constraints or color figure charges

- Immediate publication on acceptance

- Inclusion in PubMed, CAS, Scopus and Google Scholar

- Research which is freely available for redistribution 